\title{
Residual stress analysis of a micro-tubular solid oxide fuel cell
}

Wei Konga,*, Wenxuan Zhang ${ }^{\mathrm{a}}$, Shundong Zhang ${ }^{\mathrm{a}}$, Qiang Zhang ${ }^{\mathrm{a}}$, and Shichuan $\mathrm{Su}^{\mathrm{a}}$

${ }^{a}$ School of Energy and Power Engineering, Jiangsu University of Science and Technology, 212003, Zhenjiang, Jiangsu, China

*Corresponding author, E-mail addresses: wkong @ just.edu.cn;

Tel.: +86-511-84417398; Fax: +86-511-84404433.

\begin{abstract}
:
A two-dimensional axisymmetric micro-tubular solid oxide fuel cell (MT-SOFC) model is developed to study the influence of component (anode, cathode or electrolyte) thickness on residual stress at the room temperature. The results show that the anode is mainly subjected to tension stress while electrolyte and cathode are mostly exposed to compressive stress. However, the stress in a component can be reduced by increasing its thickness with other components unchanged. Then the Weibull analysis method is adopted to calculate the failure probability of the anode, it is found that the anode is prone to failure with a thinner anode or thicker cathode and electrolyte; the electrolyte thickness has a more significant effect on the anode failure probability than the cathode; and the component thickness must be coordinated in order to maximize the mechanical performance. The formula of the minimum anode thickness under the failure probability criterion 1E-6 is given, which brings considerable convenience to the design of MT-SOFC.
\end{abstract}

Key words: Micro-tubular solid oxide fuel cell (MT-SOFC); Residual stress; Electrode thickness; Failure probability. 


\section{Introduction}

The solid oxide fuel cell (SOFC) has been recognized as an alternative power generation device for its high efficiency, low emission, fuel flexibility and all-solid-state characteristic [1-4]. Among various SOFC designs, planar and tubular are the most maturely developed types $[5,6]$. For the tubular configuration, the Micro-tubular SOFC (MT-SOFC) possesses great advantages over conventional tubular SOFC (T-SOFC) and planar SOFC (P-SOFC), such as higher power density, higher mass transfer efficiency, stronger mechanical property and lower thermal stress $[7,8]$.

However, the MT-SOFC development still encounters a lot of issues: on the one hand, the cell's mechanical strength is disturbed due to the fine micro-tubular structure, which will limit the output power; on the other hand, it is a challenging work to fabricate and assemble the cells because of its micro-scale. One of the main reasons for MT-SOFC's short lifetime is the internal stress, which would finally crack and damage the cell during a long-time impact. So the fracture and failure of MT-SOFC can be predicted by analyzing the internal stress.

The thermal stress of SOFC has been widely studied in experiments [9-12] and numerical model [13-16], especially for the P-SOFC: Chen et al. [17] constructed a three-dimensional finite element analysis model and investigated the status of thermal stress in a single P-SOFC induced by a uniform temperature field. Nakajo et al. [18] established a multi-physics model and studied the stress of SOFC when they are in operation state and cool-down phase. Yakabe et al. [11, 19] built a three-dimensional 
model of anode-supported P-SOFC with STAR-CD to analyze residual stress in electrolyte. Selimovic et al. [20] focused on the stress in P-SOFC caused by the thermal expansion incompatibility under high temperature gradients during steady and dynamic operation. Fan et al. [21] researched the thermal stress distribution in the positive electrode-electrolyte-negative electrode (PEN) via a finite element model. And Weil et al. [22] investigated the stress performance of the new bonded compliant seal (BCS) utilizing the ANSYS. However, in contrast to the intensive reports on mechanical property of P-SOFC, the studies about MT-SOFC's stress are few and recent. Serincan et al. [23] and Cui et al. [24] reported a MT-SOFC multi-physics model, then investigated the internal stress based on the temperature obtained from the thermal-fluid model; $\mathrm{Xu}$ et al. [25] did some researches aiming at the influence of operation temperature and temperature gradient on the state of the stress. Nevertheless, the effect of MT-SOFC component (anode, cathode or electrolyte) thickness on the stress distribution and the failure probability hasn't been studied in detail and the component thickness is irregularly chosen with little concern for stress stability, which is unfavorable for the long term stability of MT-SOFC [26-29].

In this study, a two-dimensional (2D) axisymmetric model is established and validated to analysis the effect of component thickness on the residual stress and the failure probability, then the minimum anode thickness under the failure criterion 1E-6 is carefully commented.

\section{Numerical Model}

\subsection{Structural mechanics relation}


It is assumed that the MT-SOFC materials in this model meet the linear elastic theory. The total strain consisting of elastic strain, thermal strain and initial strain can be written as:

$$
\varepsilon=\varepsilon_{e l}+\varepsilon_{t h}+\varepsilon_{0}
$$

where $\varepsilon$ is the total strain, $\varepsilon_{e l}$ is the elastic strain, $\varepsilon_{t h}$ is the thermal strain, $\varepsilon_{0}$ is the initial strain. In which, the thermal strain can be expressed as:

$$
\varepsilon_{t h}=\alpha\left(T-T_{f}\right)
$$

where $\alpha$ denotes the thermal expansion coefficient of the material; $T$ refers to local temperature where thermal stress is determined; $T_{f}$ represents the stress-free temperature corresponding to thermal stress of zero.

Therefore, the stress could be expressed as:

$$
\sigma=D \varepsilon_{e l}+\sigma_{0}=D\left(\varepsilon-\varepsilon_{t h}-\varepsilon_{0}\right)+\sigma_{0}
$$

where $\sigma$ is the stress vector, $D$ represents the elasticity matrix, $\sigma_{0}$ is the initial stress. For isotropic material, elasticity matrix $D$ is:

$$
D=\frac{E}{(1+v)(1-2 v)}\left[\begin{array}{cccc}
1-v & v & v & 0 \\
v & 1-v & v & 0 \\
v & v & 1-v & 0 \\
0 & 0 & 0 & \frac{1-2 v}{2}
\end{array}\right]
$$

where $E$ is the Young's modulus and $v$ is the Poisson's ratio.

\subsection{Geometric model}

An anode-supported MT-SOFC three-dimensional model is schematically showed in Fig. 1a, which is composed of cathode, electrolyte and anode from outside to inside. In this manner, the fuel goes through the inner anode tube and the air 
contacts with outer cathode in order to supply oxygen advantageously. However, considering the axisymmetric structure, the computational domain can be simplified into a 2D section as shown in Fig. 1b.

The detailed input parameters of the model are summarized in Table 1.

\subsection{Mechanical property of materials}

This study here focused on the most typical MT-SOFC in configuration of porous composite Ni-YSZ anode/dense YSZ electrolyte/porous composite LSM-YSZ cathode, the effective properties of the porous composite can be calculated by following method [30].

The bulk modulus $K_{\text {com }}$ and shear modulus $G_{\text {com }}$ of the dense composite material are attained by:

$$
\begin{gathered}
K_{\text {com }}=K_{2}+\frac{\varphi_{1}}{1 /\left(K_{1}-K_{2}\right)+3 \varphi_{2} /\left(3 K_{2}+4 G_{2}\right)} \\
G_{c o m}=G_{2}+\frac{\varphi_{1}}{1 /\left(G_{1}-G_{2}\right)+6 \varphi_{2}\left(3 K_{2}+2 G_{2}\right) /\left(5 G_{2}\left(3 K_{2}+4 G_{2}\right)\right)}
\end{gathered}
$$

where $K_{i}$ and $G_{i}$ are the bulk and shear modulus of material $i$, respectively, $\varphi_{i}$ denotes the volume fraction of material $i$.

The Young's modulus of the dense composite materials $E_{c o m}$ is calculated by:

$$
E_{c o m}=\frac{9 K_{c o m} G_{c o m}}{3 K_{c o m}+G_{c o m}}
$$

The thermal expansion coefficient of the two-phase composite dense material $\alpha_{c o m}$ is given by:

$$
\alpha_{c o m}=\frac{\alpha_{1} \varphi_{1} K_{1}+\alpha_{2} \varphi_{2} K_{2}}{\varphi_{1} K_{1}+\varphi_{2} K_{2}}
$$


The effective Young's modulus $E_{\text {eff }}$ and shear modulus $G_{e f f}$ of the porous electrodes are calculated by:

$$
\begin{gathered}
E_{\text {eff }}=E_{\text {com }} \frac{\left(1-\phi_{\mathrm{g}}\right)^{2}}{1+\phi_{\mathrm{g}}\left(2-3 v_{\text {com }}\right)} \\
G_{e f f}=G_{c o m} \frac{\left(1-\phi_{\mathrm{g}}\right)^{2}}{1+\phi_{\mathrm{g}}\left(11-19 v_{\text {com }}\right) /\left(4+4 v_{\text {com }}\right)}
\end{gathered}
$$

where $\phi_{\mathrm{g}}$ is the porosity, the subscript "com" represents the effective properties of dense material.

The effective Poisson's ratio of the porous electrode $v_{\text {eff }}$ is:

$$
v_{e f f}=\frac{1}{4} \frac{4 v_{c o m}+3 \phi_{\mathrm{g}}-7 v_{c o m} \phi_{\mathrm{g}}}{1+2 \phi_{\mathrm{g}}-3 v_{c o m} \phi_{\mathrm{g}}}
$$

Density of the porous electrode $\rho_{\text {eff }}$ :

$$
\rho_{\text {eff }}=\left(\varphi_{1} \rho_{1}+\varphi_{2} \rho_{2}\right)\left(1-\phi_{\mathrm{g}}\right)
$$

The properties of dense material at the room temperature are listed in Table 2.

\subsection{Failure probability analysis}

Ceramic material fractures easily under certain stress intensity due to the brittle nature, its failure probability can be determined by Weibull method. For MT-SOFC, the failure probability mainly depends on three principal stresses because the MT-SOFC is subjected to multidirectional stresses, so it can be written as:

$$
P_{f}=1-\prod_{i=1}^{3} \exp \left(-\int_{V}\left(\frac{\sigma_{i}}{\sigma_{0}}\right)^{m} \frac{d V}{V_{0}}\right)
$$

where $V_{0}$ is the reference volume, $V$ is the volume of the SOFC component, $\sigma_{0}$ represents the Weibull strength , $m$ signifies the Weibull modulus and $\sigma_{i}(i=1,2$, 3 ) is the first, second, and third principal stress, respectively. According to the 
definition of principal stress, there is $\sigma_{1}>\sigma_{2}>\sigma_{3}$, meanwhile, a positive $\sigma_{i}$ represents tensile stress and a negative $\sigma_{i}$ means compressive stress. It is noteworthy that the Weibull method can only be applied to the tensile stress.

\subsection{Model validation}

The model is verified by comparing the distribution and magnitude of the three principal radial stresses at room temperature with model data from literature [30]. The first and second principal stresses are shown in the Fig. 2a, and the third principal stress is presented in Fig. 2b. It is readily noticeable that the distribution of the principal stresses from this model are in good agreement with the literature data, which proves the validity of the model and qualifies the model for a reliable further study.

\section{Result and discussion}

\subsection{Residual stress}

During the sintering process of the MT-SOFC, the anode and electrolyte are assumed to have the same stress free temperature of $1473 \mathrm{~K}$, and that of cathode is $1373 \mathrm{~K}$ [30]. The residual stress arises from different thermal expansion coefficient between materials while the MT-SOFC cools down from sintering temperature to room temperature. The maximum residual principal stress at room temperature is shown in Fig. 3 in which the positive value represents tensile stress and the negative one represents compressive stress. It easy to point out that the anode is mainly subjected to tension stress while electrolyte and cathode are mostly exposed to compressive stress, which is because that the thermal expansion coefficient of anode 
is greater than that of electrolyte and cathode. The influence of component thicknesses on residual stress is systematically investigated via parameter sweep.

The effects of anode thickness on the residual stress in anode, electrolyte and cathode are demonstrated in Fig. 3a. The tensile stress in anode is decreasing with the increase in anode thickness duo to the stress release in the thick anode. However, the compressive stresses in the electrolyte and cathode are increasing. With anode thickness of $0.2 \mathrm{~mm}$, the maximum residual principal stress in anode, electrolyte and cathode are $5.19 \times 10^{7} \mathrm{~Pa},-7.36 \times 10^{8} \mathrm{~Pa},-7.94 \times 10^{7} \mathrm{~Pa}$, respectively. When the anode thickness increases to $1.0 \mathrm{~mm}$, the compressive stresses in electrolyte and cathode reaches $8.58 \times 10^{8} \mathrm{~Pa}$ and $9.56 \times 10^{7} \mathrm{~Pa}$, respectively, both are on the verge of their compressive strength $1 \mathrm{GPa}$ [19] and $100 \mathrm{MPa}$ [31]. As a consequence, the anode thickness in the MT-SOFC should be appropriate to avoid the stresses in electrolyte or cathode exceeding their compressive strength.

Shown in Fig. 3b is the impact of electrolyte thickness on the residual stress. A thick electrolyte tends to raise the tensile stress in the anode, but the compressive stresses in the electrolyte and cathode can be reduced. In other words, increase in electrolyte thickness can enhance the mechanical stability of the electrolyte and cathode. The tensile stress in the anode increased from $5.19 \times 10^{7} \mathrm{~Pa}$ to $1.40 \times 10^{8} \mathrm{~Pa}$ along the electrolyte thickness from $10 \mu \mathrm{m}$ to $50 \mu \mathrm{m}$. Nevertheless, the ceramic electrodes is quite sensitive to the tensile stress, so the electrolyte also cannot be too thick and usually selected in the range of $10 \mu \mathrm{m}-20 \mu \mathrm{m}[24,28,29,32-42]$.

The plot in Fig. 3c shows the evolution of residual stress with the thickening of 
cathode. The stresses in the electrolyte and cathode are inversely proportional to the cathode thickness, but the anode stress is opposite. In brief, the mechanical property of electrolyte and cathode can be enhanced with the thick cathode. With the cathode increased from $10 \mu \mathrm{m}$ to $80 \mu \mathrm{m}$, the compressive stress in the cathode and electrolyte decreased by $1.18 \times 10^{7} \mathrm{~Pa}$ and $6.20 \times 10^{7} \mathrm{~Pa}$ respectively. As a comparison, in Fig. 3b, with the electrolyte increased from $10 \mu \mathrm{m}$ to $50 \mu \mathrm{m}$. The decrements are $4.07 \times 10^{7} \mathrm{~Pa}$ and $2.60 \times 10^{8} \mathrm{~Pa}$ for cathode and electrolyte respectively. As a conclusion, the electrolyte has a more significant impact on the residual stress than cathode.

As a brittle material, ceramic is more sensitive to tensile stress than compressive stress because its compressive strength is much higher than tensile strength. A SOFC can be judged failure if the compressive stress exceed compressive strength [30]. Therefore, it is vital to keep the maximum compressive stress in electrolyte and cathode lower than respective compressive strength. However, the life time of the whole MT-SOFC is more dependent on the anode with its tensile stress. For the ceramic material in tensile state, Weibull method is an effective tool to analyze the failure probability. So in this paper, the failure probability is used to evaluate the mechanical performance of the tensile stress suffered anode.

\subsection{Failure probability of the anode}

Since the tensile stress suffered anode is more likely to failure than electrolyte and cathode, here Weibull analysis was performed to analyze its failure probability. The criterion of the failure probability is elected as 1E-6 according to the practical application of SOFC [43]. In order to investigate the effect of component thickness on 
the failure probability of the anode, the failure probability of anode was calculated independently via changing the thickness of anode, electrolyte and cathode.

The failure probabilities of anode under different electrolyte thicknesses are displayed in Fig. 4. The result reveals that the failure probability of anode increases with increasing the electrolyte thickness, e.g. for a $0.2 \mathrm{~mm}$ thick anode, the failure probability increased by two orders of magnitude from $1.54 \times 10^{-6}$ to $4.92 \times 10^{-4}$ when the electrolyte increased from $10 \mu \mathrm{m}$ to $20 \mu \mathrm{m}$. Under the adopted failure probability criterion 1E-6, the minimum thicknesses of the anode are $0.263 \mathrm{~mm}, 0.554 \mathrm{~mm}, 1.024$ $\mathrm{mm}$ corresponding to the electrolyte thickness $10 \mu \mathrm{m}, 20 \mu \mathrm{m}, 30 \mu \mathrm{m}$, which indicates that a thick electrolyte needs to match with thick anode, but it may result in a high Ohmic polarization. Therefore, in order to prevent the MT-SOFC from failure, the electrolyte thickness should be appropriately determined.

Fig. 5 shows influence of cathode thickness on the failure probabilities of anode. The increase of cathode thickness will cause the increase of the failure probability for anode, but the effect is not as significant as that of electrolyte thickness, e.g. the failure probability of anode only increased from $1.54 \times 10^{-6}$ to $3.39 \times 10^{-6}$ when the cathode thickness increased from $10 \mu \mathrm{m}$ to $20 \mu \mathrm{m}$ under the anode thickness of 0.2 $\mathrm{mm}$, the increase is much smaller compared to that introduced by electrolyte thickness. The minimum anode thicknesses of the MT-SOFC should be $0.235 \mathrm{~mm}, 0.263 \mathrm{~mm}$, $0.292 \mathrm{~mm}, 0.321 \mathrm{~mm}, 0.350 \mathrm{~mm}, 0.380 \mathrm{~mm}$ corresponding to the cathode thickness $10 \mu \mathrm{m}, 20 \mu \mathrm{m}, 30 \mu \mathrm{m}, 40 \mu \mathrm{m}, 50 \mu \mathrm{m}, 60 \mu \mathrm{m}$, an approximately linear increase in accordance with criterion 1E-6. But thick cathode also needs to match with thick 
anode, which raises the cost and is not favorable to the commercialization of MT-SOFC.

\subsection{The relationship among the thicknesses of the anode, electrolyte and cathode}

According to study of the residual stress and the failure probability, it is obvious that the thickness of the anode, electrolyte and cathode should meet a certain relationship to make the MT-SOFC has higher mechanical stability and long life.

The relationship among the thicknesses of anode, electrolyte and cathode when the failure probability equals to $1 \mathrm{E}-6$ is shown in Fig. 6. The range of electrolyte thickness is usually in $10-20 \mu \mathrm{m}[24,28,29,32-42]$ in the literature with respect to the MT-SOFC. According to straight line plots, the relationship between anode thickness and cathode thickness is approximately linear at a fixed electrolyte thickness.

Therefore, the minimum anode thickness is related to the cathode thickness via following correlation:

$$
t_{\text {min-anode }}=A+B \times t_{\text {cathode }}
$$

where $\mathrm{A}$ is intercept and B is slope. The values of A and B with different electrolyte thickness are shown in Fig. 7. In this fashion, the minimum anode thickness can be easily determined.

As a further study of Fig. 7a, it can be found that the A and the electrolyte thickness are in linear relationship, which can be expressed as:

$$
A=0.0287 t_{\text {electrolyte }}-0.0839
$$

Moreover, Fig. 7b displays the relation between the B and electrolyte thickness. 
It is clear that the value of B increases from 0.0029 to 0.0047 with increase of the electrolyte thickness from $10 \mu \mathrm{m}$ to $20 \mu \mathrm{m}$, so the B must be related to electrolyte thickness. Then the relationship can be considered as:

$$
B=1.2 \times 10^{-5} t_{\text {electrolyte }}^{2}-3.04 \times 10^{-4} t_{\text {electrolyte }}+0.0048
$$

As a result, the relationship among the thicknesses of the anode, electrolyte and cathode can be attained by:

$$
t_{\min -\text { anode }}=\left(0.0287 t_{\text {electrolyte }}-0.0839\right)+\left(1.2 \times 10^{-5} t_{\text {electrolyte }}^{2}-3.04 \times 10^{-4} t_{\text {electrolyte }}+0.0048\right) t_{\text {cathode }}
$$

where the unit of the $t_{\min -a n o d e}$ is [mm] and $t_{\text {electrolyte }}$ and $t_{\text {cathode }}$ are in $[\mu \mathrm{m}]$.

Once the thicknesses of two layers are given, the thickness of the third one can be acquired precisely by this equation, which brings considerable convenience to the design of MT-SOFC. But it is important to keep in mind that Eq. 17 is derived under the failure probability criterion of $1 \mathrm{E}-6$.

\section{Conclusions}

A well verified MT-SOFC 2D axisymmetric model has been established in this study to investigate the effect of component thickness on residual stress and failure probability. Based on this model, parametric study and Weibull analysis are implemented to study the residual stress and failure probability, respectively. The most important conclusions are summarized as follows:

(1) The anode mainly undergoes tension stress while electrolyte and cathode mostly suffer compressive stress.

(2) For a chosen component (which means the dimensions of other components are fixed), the stress decreases with increasing its thickness. 
(3) The failure probability of anode decreases with the increase of anode thickness or the decrease of electrolyte and cathode thicknesses.

(4) The influence of cathode thickness on the failure probability is weaker than electrylote thickness.

(5) A simply relationship among the thicknesses of anode, electrolyte and cathode under the failure probability criterion $1 \mathrm{E}-6$ can be written as:

$t_{\min -\text { anode }}=\left(0.0287 t_{\text {electrolyte }}-0.0839\right)+\left(1.2 \times 10^{-5} t_{\text {electrolyte }}^{2}-3.04 \times 10^{-4} t_{\text {electrolyte }}+0.0048\right) t_{\text {cathode }}$

The conclusions derived from this study have practical significance to improve mechanical stability and prolong the lifetime of MT-SOFC, which will benefit the application of the MT-SOFC.

\section{Acknowledgements}

We gratefully acknowledge the financial support of the National Science Foundation of China (21406095), the Jiangsu Province Colleges and Universities Natural Science Projects (13KJB480003) and Colleges and universities in Jiangsu high-tech ship collaborative innovation center/Jiangsu University of Science and Technology institute of Marine equipment (HZ2016016). 


\section{References}

[1] Su S, He H, Chen D, Zhu W, Wu Y, Kong W, et al. Flow distribution analyzing for the solid oxide fuel cell short stacks with rectangular and discrete cylindrical rib configurations. Int J Hydrogen Energy. 2015;40:577-92.

[2] Shao Q, Fernández-González R, Ruiz-Morales JC, Bouhala L, Fiorelli D, Younes A, et al. An advanced numerical model for energy conversion and crack growth predictions in Solid Oxide Fuel Cell units. Int J Hydrogen Energy. 2015.

[3] Andersson M, Nakajima H, Kitahara T, Shimizu A, Koshiyama T, Paradis H, et al. Comparison of humidified hydrogen and partly pre-reformed natural gas as fuel for solid oxide fuel cells applying computational fluid dynamics. Int J Heat Mass Transfer. 2014;77:1008-22.

[4] Cao Z, Zhang Y, Miao J, Wang Z, Lü Z, Sui Y, et al. Titanium-substituted lanthanum strontium ferrite as a novel electrode material for symmetrical solid oxide fuel cell. Int J Hydrogen Energy. 2015;40:16572-7.

[5] Han Z, Wang Y, Yang Z, Han M. Electrochemical Properties of Tubular SOFC Based on a Porous Ceramic Support Fabricated by Phase-Inversion Method. J Materials Science \& Technology. 2016.

[6] Zhang Z, Yue D, Yang G, Chen J, Zheng Y, Miao H, et al. Three-dimensional CFD modeling of transport phenomena in multi-channel anode-supported planar SOFCs. Int J Heat Mass Transfer. 2015;84:942-54.

[7] Laguna-Bercero MA, Hanifi AR, Etsell TH, Sarkar P, Orera VM. Microtubular solid oxide fuel cells with lanthanum strontium manganite infiltrated cathodes. Int $\mathbf{J}$ Hydrogen Energy. 2015;40:5469-74.

[8] Howe KS, Hanifi AR, Kendall K, Zazulak M, Etsell TH, Sarkar P. Performance of microtubular SOFCs with infiltrated electrodes under thermal cycling. Int J Hydrogen Energy. 2013;38:1058-67.

[9] Malzbender J, Fischer W, Steinbrech RW. Studies of residual stresses in planar solid oxide fuel cells. J Power Sources. 2008;182:594-8.

[10] Frandsen HL, Ramos T, Faes A, Pihlatie M, Brodersen K. Optimization of the strength of SOFC anode supports. J Eur Ceram Soc. 2012;32:1041-52.

[11] Yakabe H, Baba Y, Sakurai T, Satoh M, Hirosawa I, Yoda Y. Evaluation of residual stresses in a SOFC stack. J Power Sources. 2004;131:278-84.

[12] Fischer W, Malzbender J, Blass G, Steinbrech RW. Residual stresses in planar solid oxide fuel cells. J Power Sources. 2005;150:73-7.

[13] Peksen M. 3D CFD/FEM analysis of thermomechanical long-term behaviour in SOFCs: Furnace operation with different fuel gases. Int J Hydrogen Energy. 2015;40:12362-9.

[14] Vaidya S, Kim J-H. Finite element thermal stress analysis of solid oxide fuel cell cathode microstructures. J Power Sources. 2013;225:269-76.

[15] Celik S, Ibrahimoglu B, Toros S, Mat MD. Three dimensional stress analysis of solid oxide fuel cell anode micro structure. Int J Hydrogen Energy. 2014;39:19119-31. [16] Pianko-Oprych P, Zinko T, Jaworski Z. Simulation of thermal stresses for new designs of microtubular Solid Oxide Fuel Cell stack. Int J Hydrogen Energy. 2015. 
[17] Chen Xian YJ, Pu Jian, Li Jian. Finite element analisis of thermal stress in planar SOFCs. J Inorg Mater. 2007;22:339-43.

[18] Nakajo A, Wuillemin Z, Van herle J, Favrat D. Simulation of thermal stresses in anode-supported solid oxide fuel cell stacks. Part I: Probability of failure of the cells. J Power Sources. 2009; 193:203-15.

[19] Yakabe H, Baba Y, Sakurai T, Yoshitaka Y. Evaluation of the residual stress for anode-supported SOFCs. J Power Sources. 2004;135:9-16.

[20] Selimovic A, Kemm M, Torisson T, Assadi M. Steady state and transient thermal stress analysis in planar solid oxide fuel cells. J Power Sources. 2005;145:463-9.

[21] Fan Pengfei ZX, Li Guojun, Liu Qian. Analysis on thermal stress of planar solid oxide fuel cell. J XI'AN JIAOTONG UNIV. 2012;46:75-81.

[22] Weil K, Koeppel B. Thermal stress analysis of the planar SOFC bonded compliant seal design. Int J Hydrogen Energy. 2008;33:3976-90.

[23] Serincan MF, Pasaogullari U, Sammes NM. Thermal stresses in an operating micro-tubular solid oxide fuel cell. J Power Sources. 2010;195:4905-14.

[24] Cui DA, Cheng MJ. Thermal stress modeling of anode supported micro-tubular solid oxide fuel cell. J Power Sources. 2009;192:400-7.

[25] Xu Yingqiang DC, Wang Leilei. Thermal stress analysis of a micro-tubular solid oxide fuel cell. Chin J Power Sources. 2013;37:1374-92.

[26] Serincan MF, Pasaogullari U, Sammes NM. Effects of operating conditions on the performance of a micro-tubular solid oxide fuel cell (SOFC). J Power Sources. 2009;192:414-22.

[27] Kim-Lohsoontorn P, Priyakorn F, Wetwatana U, Laosiripojana N. Modelling of a tubular solid oxide fuel cell with different designs of indirect internal reformer. $\mathrm{J}$ Energy Chemistry. 2014;23:251-63.

[28] López-Robledo MJ, Laguna-Bercero MA, Silva J, Orera VM, Larrea A. Electrochemical performance of intermediate temperature micro-tubular solid oxide fuel cells using porous ceria barrier layers. Ceram Int. 2015;41:7651-60.

[29] Zhang X, Lin B, Ling Y, Dong Y, Meng G, Liu X. An anode-supported micro-tubular solid oxide fuel cell with redox stable composite cathode. Int $\mathrm{J}$ Hydrogen Energy. 2010;35:8654-62.

[30] Li J, Lin Z. Effects of electrode composition on the electrochemical performance and mechanical property of micro-tubular solid oxide fuel cell. Int J Hydrogen Energy. 2012;37:12925-40.

[31] Liu X, Martin CL, Bouvard D, Di Iorio S, Laurencin J, Delette G, et al. Strength of Highly Porous Ceramic Electrodes. J Am Ceram Soc. 2011;94:3500-8.

[32] Hashimoto S, Nishino H, Liu Y, Asano K, Mori M, Funahashi Y, et al. The electrochemical cell temperature estimation of micro-tubular SOFCs during the power generation. J Power Sources. 2008;181:244-50.

[33] Chen C, Liu M, Yang L, Liu M. Anode-supported micro-tubular SOFCs fabricated by a phase-inversion and dip-coating process. Int J Hydrogen Energy. 2011;36:5604-10.

[34] Calise F, Restucccia G, Sammes N. Experimental analysis of micro-tubular solid oxide fuel cell fed by hydrogen. J Power Sources. 2010;195:1163-70. 
[35] Yang C, Jin C, Chen F. Micro-tubular solid oxide fuel cells fabricated by phase-inversion method. Electrochem Commun. 2010;12:657-60.

[36] Galloway KV, Sammes NM. Performance Degradation of Microtubular SOFCs Operating in the Intermediate-Temperature Range. $J$ Electrochem Soc. 2009;156:B526-31.

[37] Dikwal CM, Bujalski W, Kendall K. Characterization of the electrochemical performance of micro-tubular SOFC in partial reduction and oxidation conditions. $\mathrm{J}$ Power Sources. 2008; 181:267-73.

[38] Akhtar N. Modelling of novel porous inserted micro-tubular, single-chamber solid oxide fuel cells (MT-SC-SOFCs). Chem Eng J. 2012;179:277-84.

[39] Akhtar N, Decent SP, Kendall K. Numerical modelling of methane-powered micro-tubular, single-chamber solid oxide fuel cell. J Power Sources. 2010;195:7796-807.

[40] Yang C, Jin C, Liu M, Chen F. Intermediate temperature micro-tubular SOFCs with enhanced performance and thermal stability. Electrochem Commun. 2013;34:231-4.

[41] Campana R, Merino RI, Larrea A, Villarreal I, Orera VM. Fabrication, electrochemical characterization and thermal cycling of anode supported microtubular solid oxide fuel cells. J Power Sources. 2009;192:120-5.

[42] Toshiaki Yamaguchi SSb, Toshio Suzuki , Yoshinobu Fujishiro , Masanobu Awanoa. Fabrication and characterization of high performance cathode supported small-scale SOFC for intermediate temperature operation. Electrochem Commun. 2008; 10:1381-3.

[43] Nakajo A, Stiller C, Härkegård G, Bolland O. Modeling of thermal stresses and probability of survival of tubular SOFC. J Power Sources. 2006;158:287-94. 


\section{List of Tables and Figures}

Table 1 Input parameters to model

Table 2 Mechanical properties of dense material

Table 3 Weibull parameters commonly used in SOFC

Fig. 1(a) Schematic of the MT-SOFC; (b) Schematic of the 2D axisymmetric MT-SOFC model

Fig. 2 Principal radial stress distribution of cell at room temperature

Fig. 3 Maximum principal stress in the PENs with various thicknesses:

(a) $t_{\text {electrolyte }}=10 \mu \mathrm{m}, t_{\text {cathode }}=20 \mu \mathrm{m}$;

(b) $t_{\text {anode }}=0.2 \mathrm{~mm}, t_{\text {cathode }}=20 \mu \mathrm{m}$;

(c) $t_{\text {anode }}=0.2 \mathrm{~mm}, t_{\text {electrolyte }}=10 \mu \mathrm{m}$.

Fig. 4 The anode failure probability with various electrolyte thicknesses

Fig. 5 The anode failure probability with various cathode thicknesses

Fig. 6 The relationship among the thicknesses of anode/electrolyte/cathode

Fig. 7(a) The relation between the A and electrolyte thickness

Fig. 7(b) The relation between the B and electrolyte thickness 
Table 1

\begin{tabular}{ll}
\hline Input parameters to model & Value \\
\hline Inner diameter of MT-SOFC tube $(\mathrm{mm})$ & 0.85 \\
Volume fraction of Ni $\left(\varphi_{N i}\right)$ & 0.445 \\
Volume fraction of LSM $\left(\varphi_{L S M}\right)$ & 0.479 \\
Anode porosity $\left(\phi_{\mathrm{g}}\right)$ & \\
& 0.4 \\
Cathode porosity $\left(\phi_{\mathrm{g}}\right)$ & \\
& 0.4 \\
Anode length (mm) & 30 \\
Electrolyte length $(\mathrm{mm})$ & 20 \\
Cathode length $(\mathrm{mm})$ & 11.8 \\
Anode thickness $(\mathrm{mm})$ & 0.15 \\
Electrolyte thickness $(\mu \mathrm{m})$ & 12 \\
Cathode thickness $(\mu \mathrm{m})$ & 20 \\
Anode and electrolyte stress-free temperature $(\mathrm{K})$ & 1473 \\
Cathode stress-free temperature $(\mathrm{K})$ & 1373 \\
Room temperature $(\mathrm{K})$ & 298 \\
\hline
\end{tabular}


Table 2

\begin{tabular}{ccccc}
\hline Material & $\begin{array}{c}\text { Young's modulus } \\
(\mathbf{G P a})\end{array}$ & $\begin{array}{c}\text { Poisson's } \\
\text { ratio }\end{array}$ & $\begin{array}{c}\text { TEC } \\
\left(\mathbf{1 0}^{-\mathbf{6}} \mathbf{K}^{-\mathbf{1}}\right)\end{array}$ & $\begin{array}{c}\text { Density } \\
\left(\mathbf{g} / \mathbf{c m}^{\mathbf{2}}\right)\end{array}$ \\
\hline YSZ & 215 & 0.317 & 10.8 & 6.04 \\
$\mathrm{Ni}$ & 219 & 0.313 & 16.5 & 8.90 \\
LSM & 95 & 0.320 & 12.4 & 6.57 \\
\hline
\end{tabular}

Table 3

\begin{tabular}{cccc}
\hline Component & Weibull modulus & $\begin{array}{c}\text { Weibull strength } \\
(\mathbf{M P a})\end{array}$ & $\begin{array}{c}\text { Reference volume } \\
\left(\mathbf{m m}^{\mathbf{3}}\right)\end{array}$ \\
\hline Anode $(298 \mathrm{~K})$ & 11.8 & 187 & 0.587 \\
Electrolyte $(298 \mathrm{~K})$ & 7.0 & 446 & 0.350 \\
Cathode $(298 \mathrm{~K})$ & 7.0 & 52 & 1.210 \\
\hline
\end{tabular}



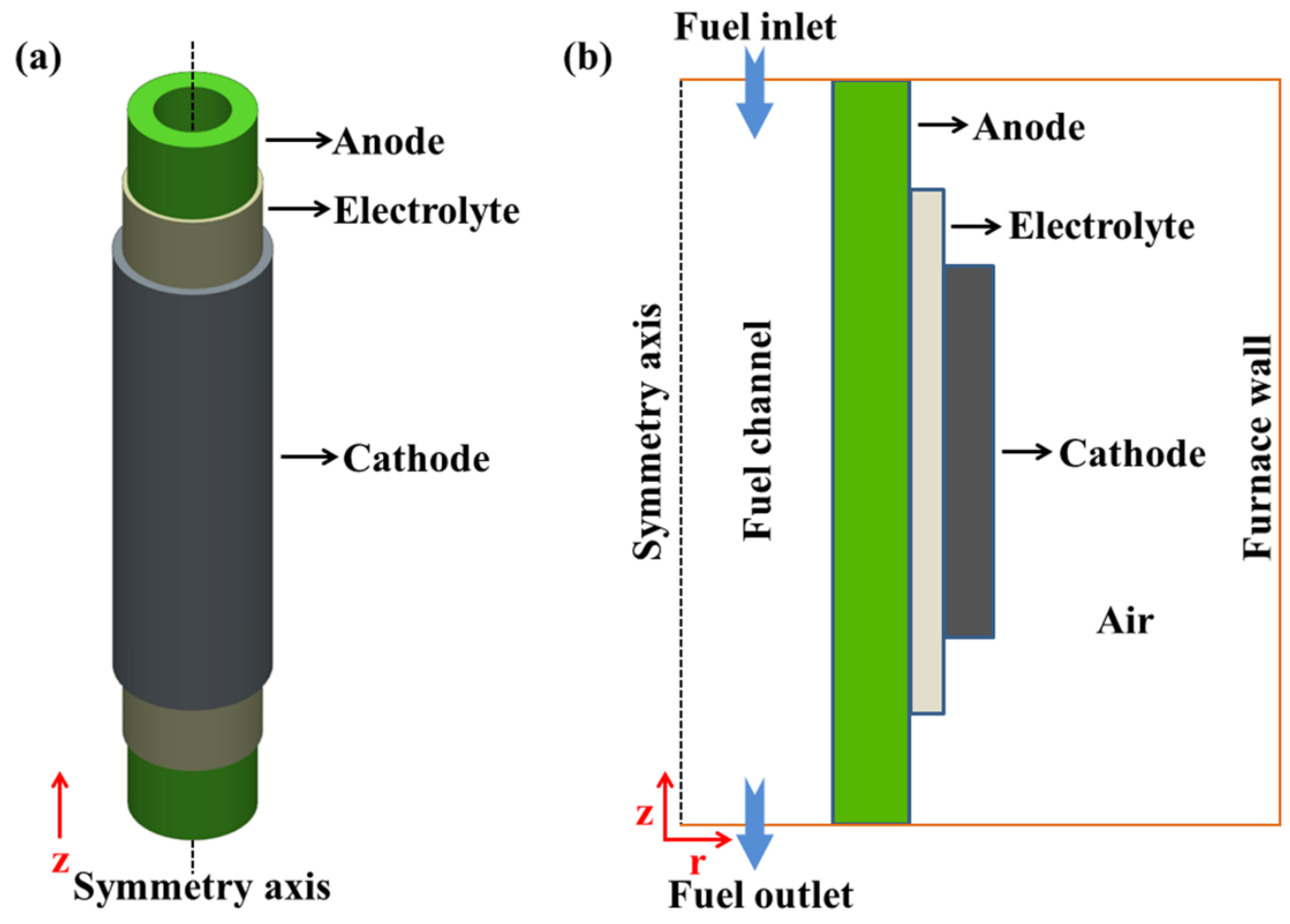

Fig. 1 


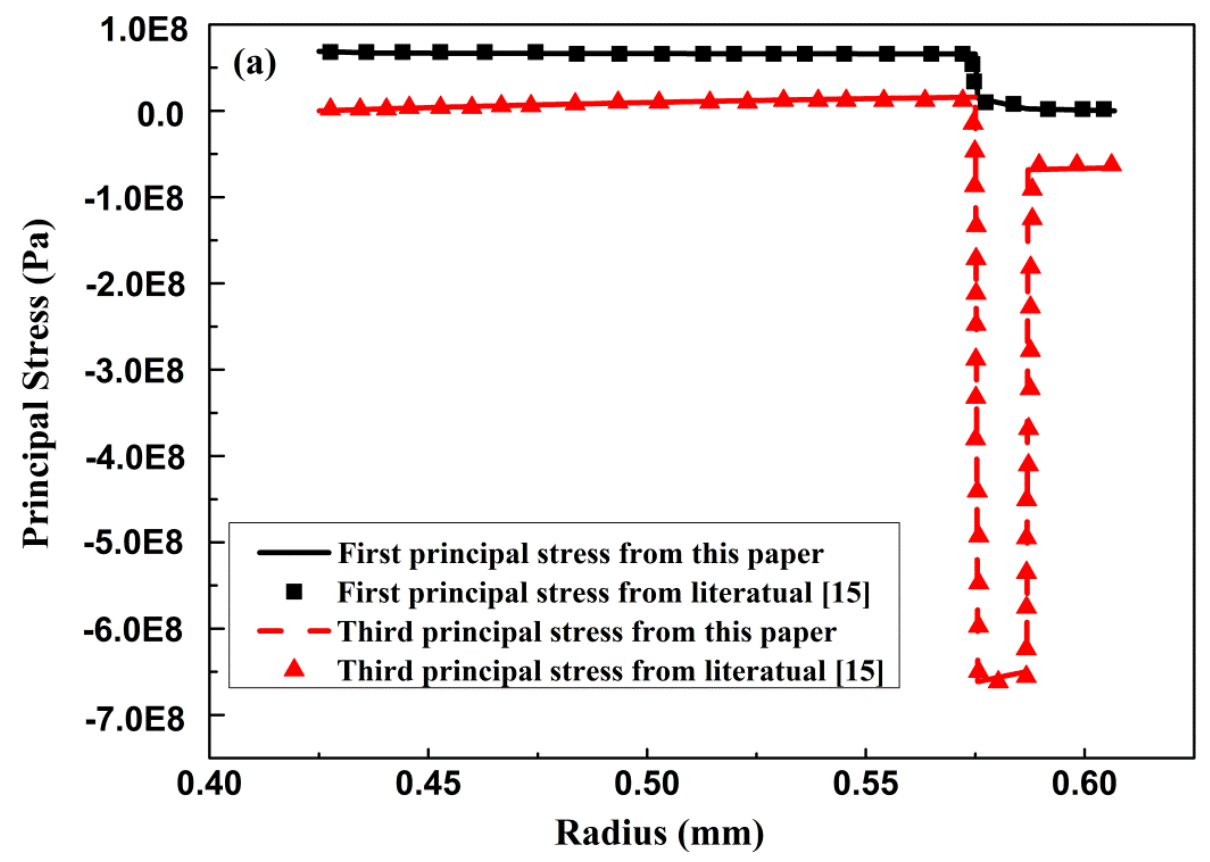

Fig. 2(a)

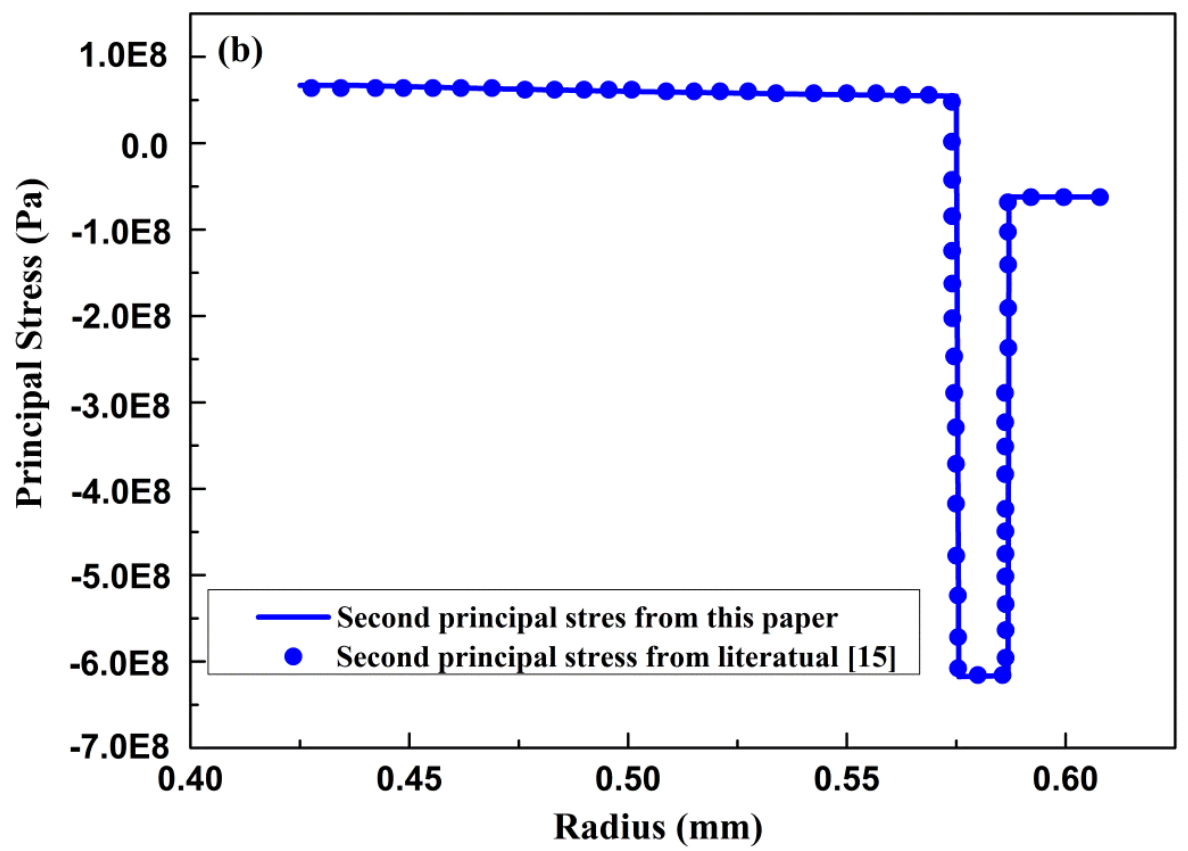

Fig. 2(b) 


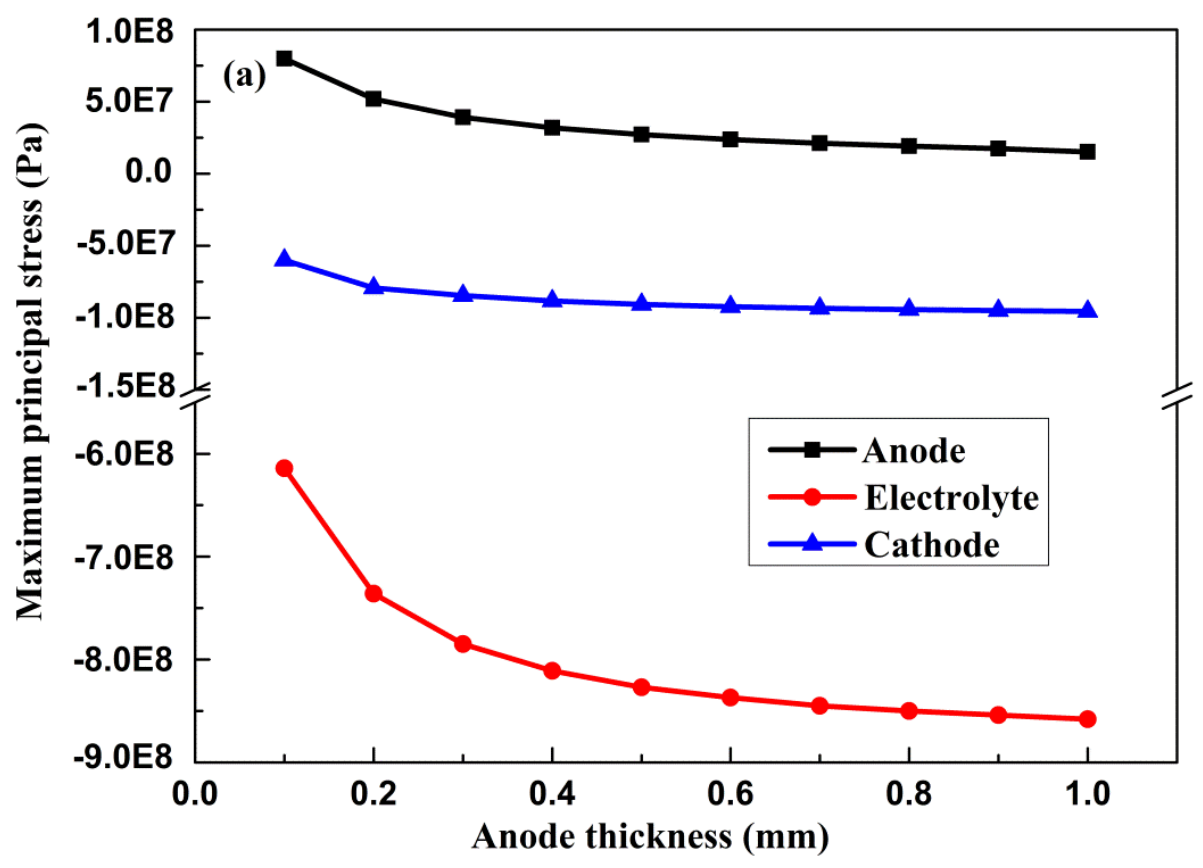

Fig. 3(a)

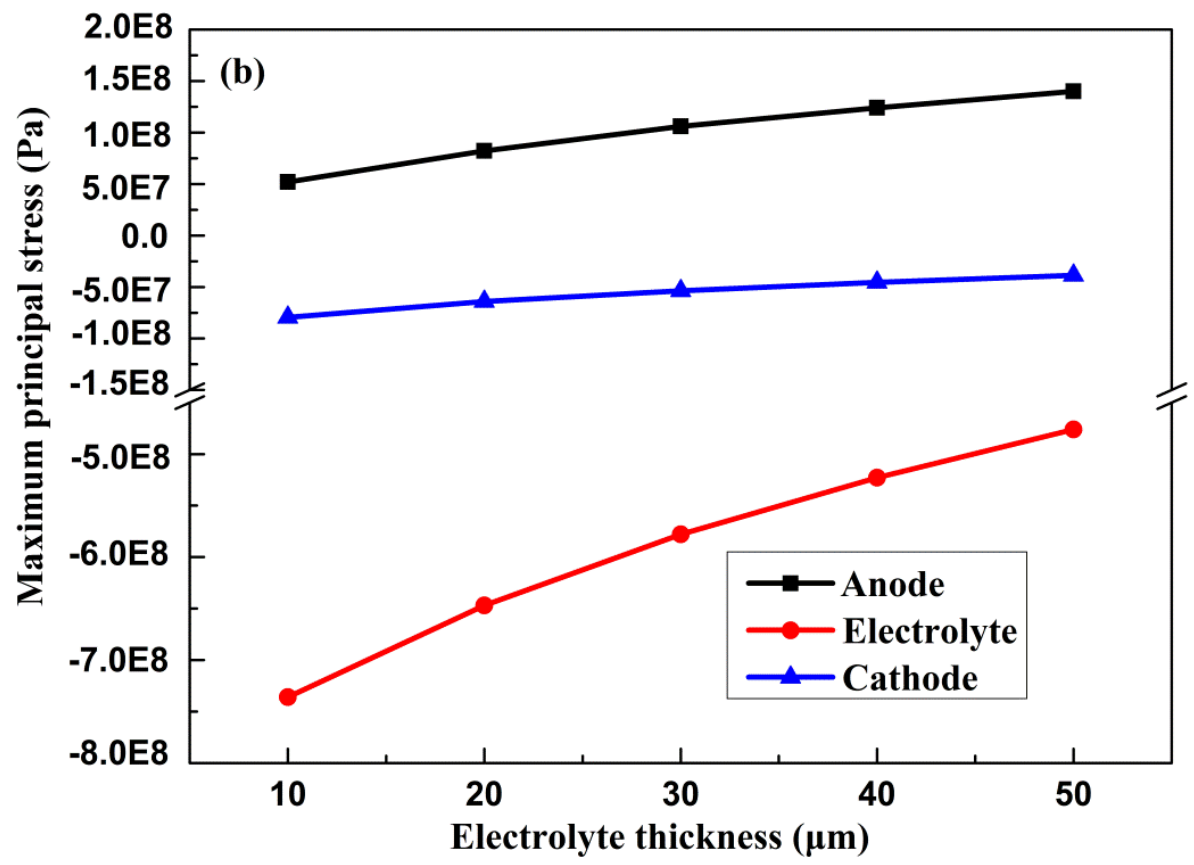

Fig. 3(b) 


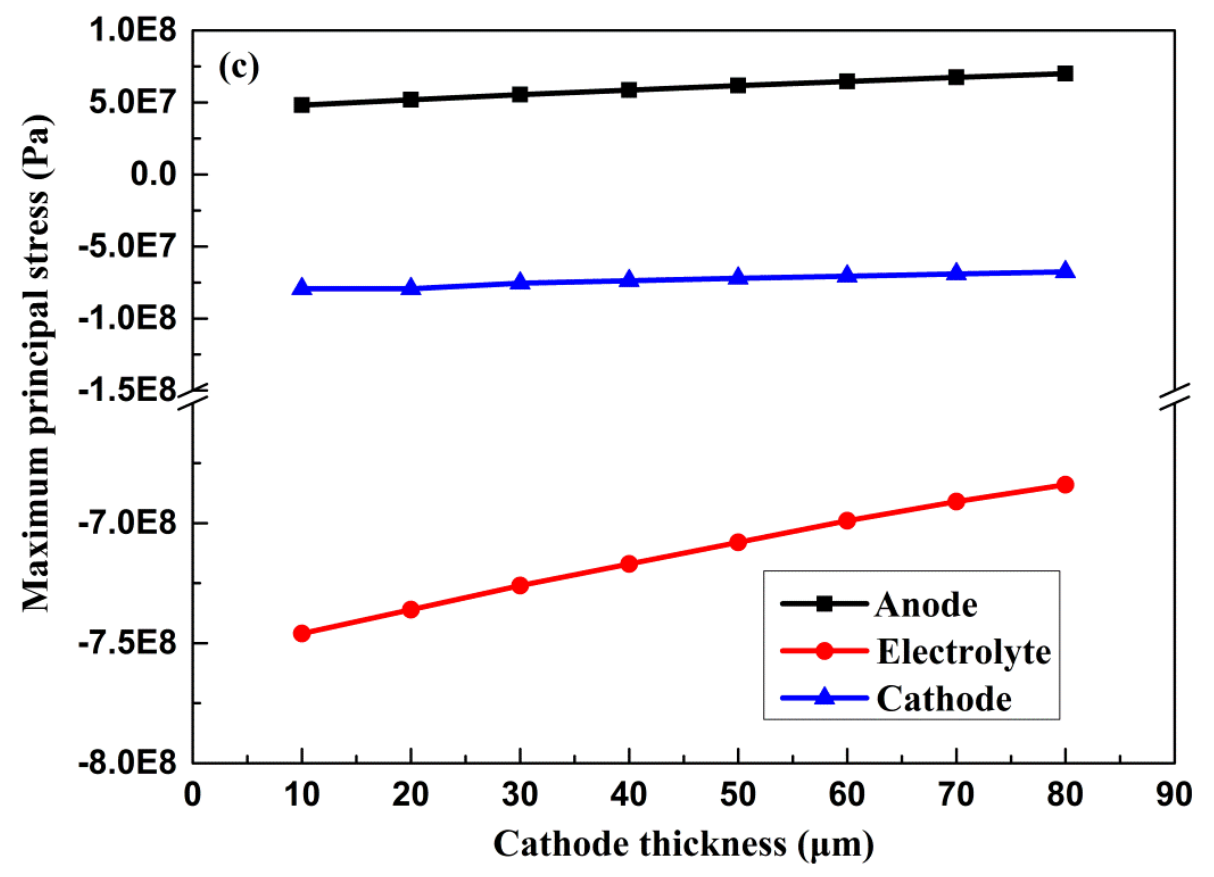

Fig. 3(c) 


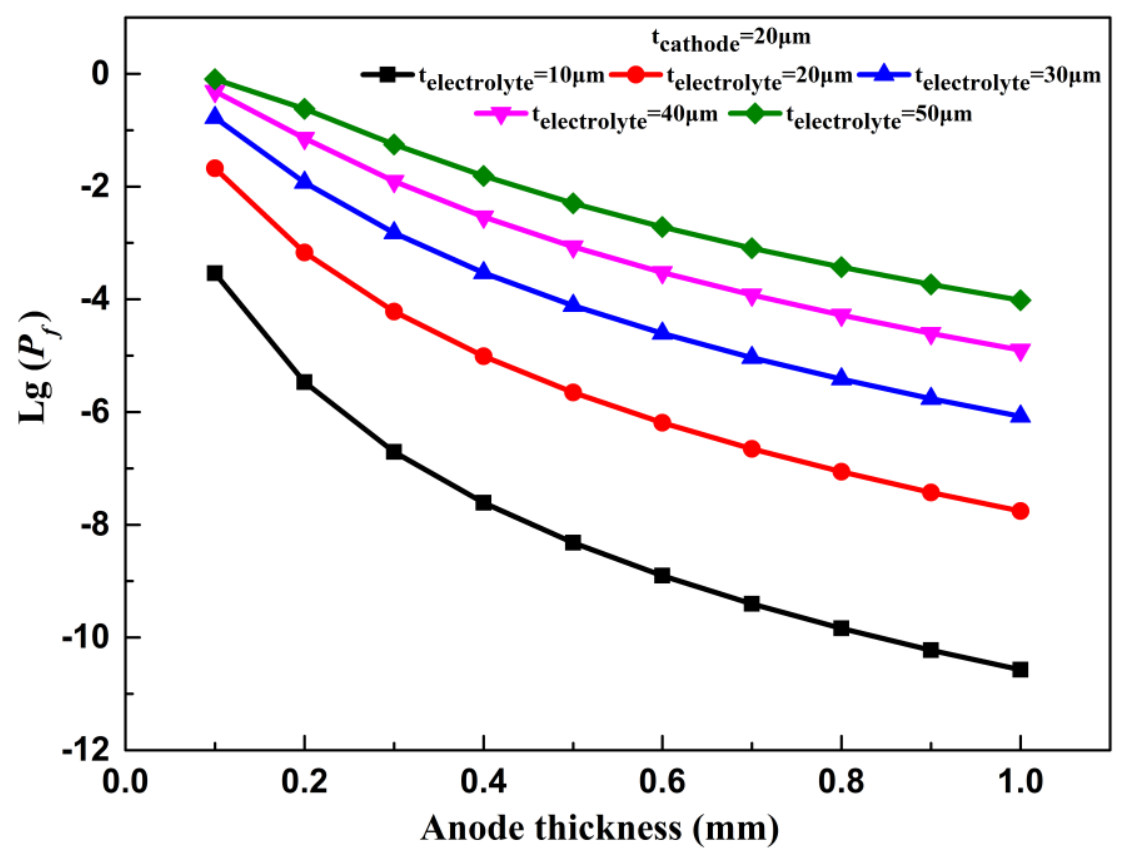

Fig. 4 


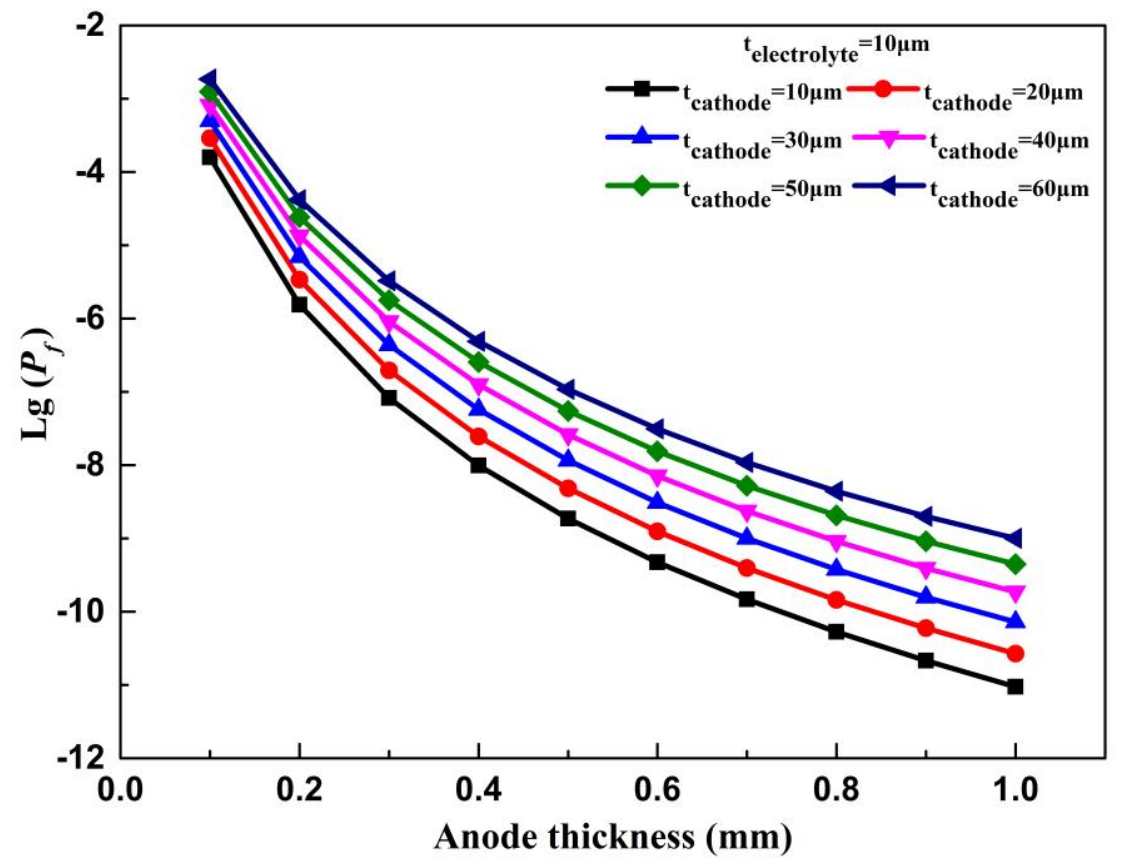

Fig. 5 


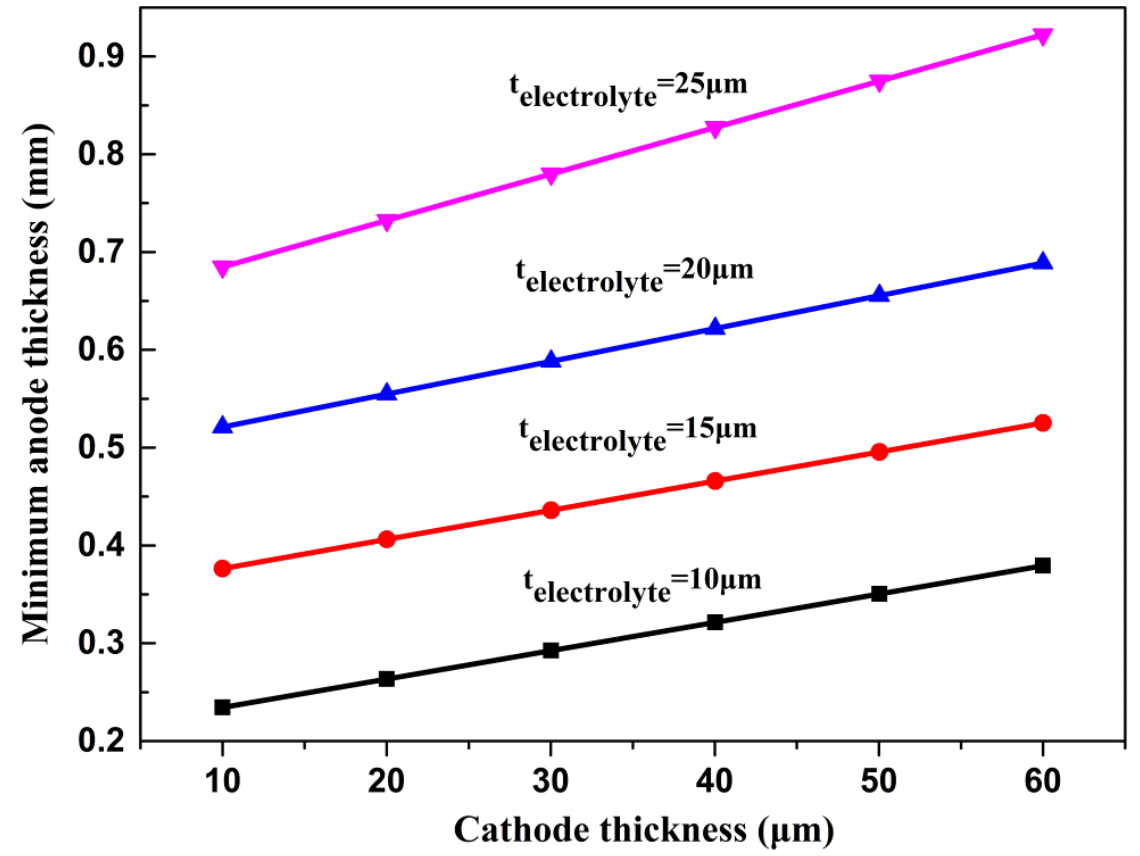

Fig. 6 


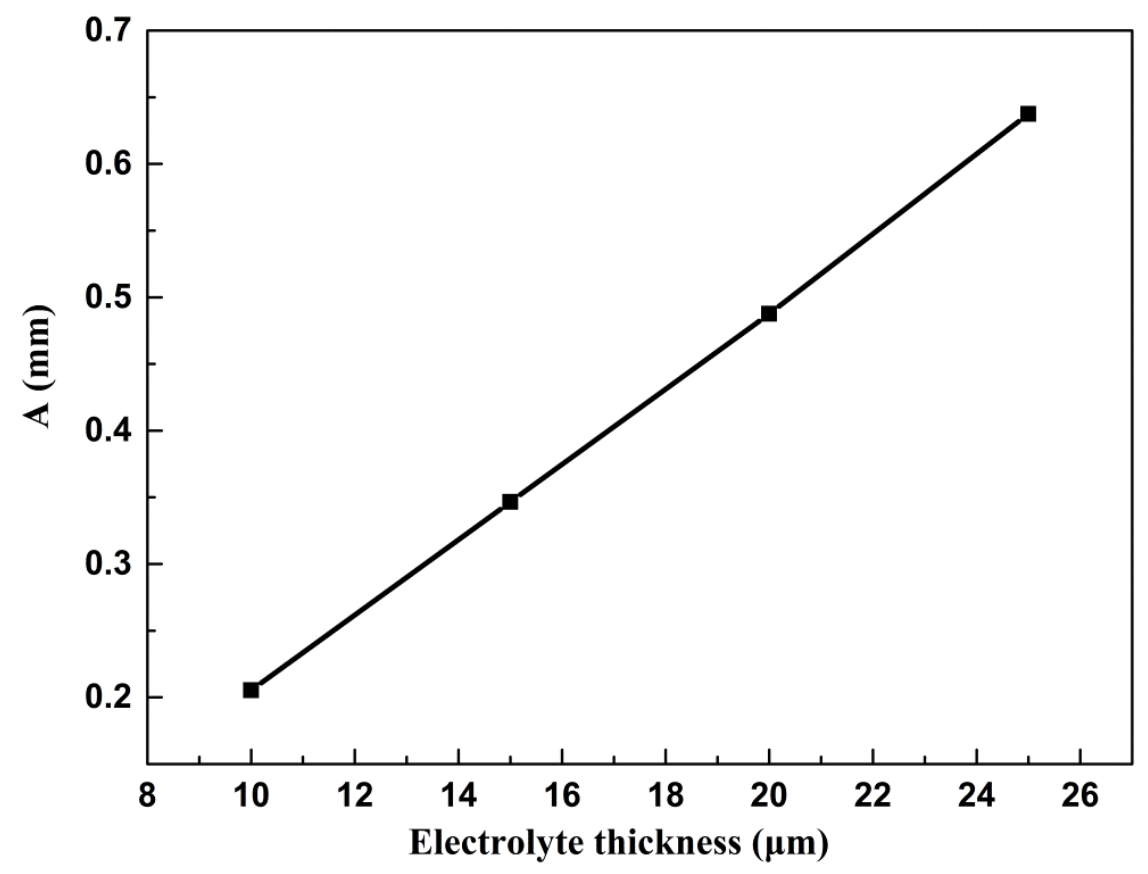

Fig. 7(a)

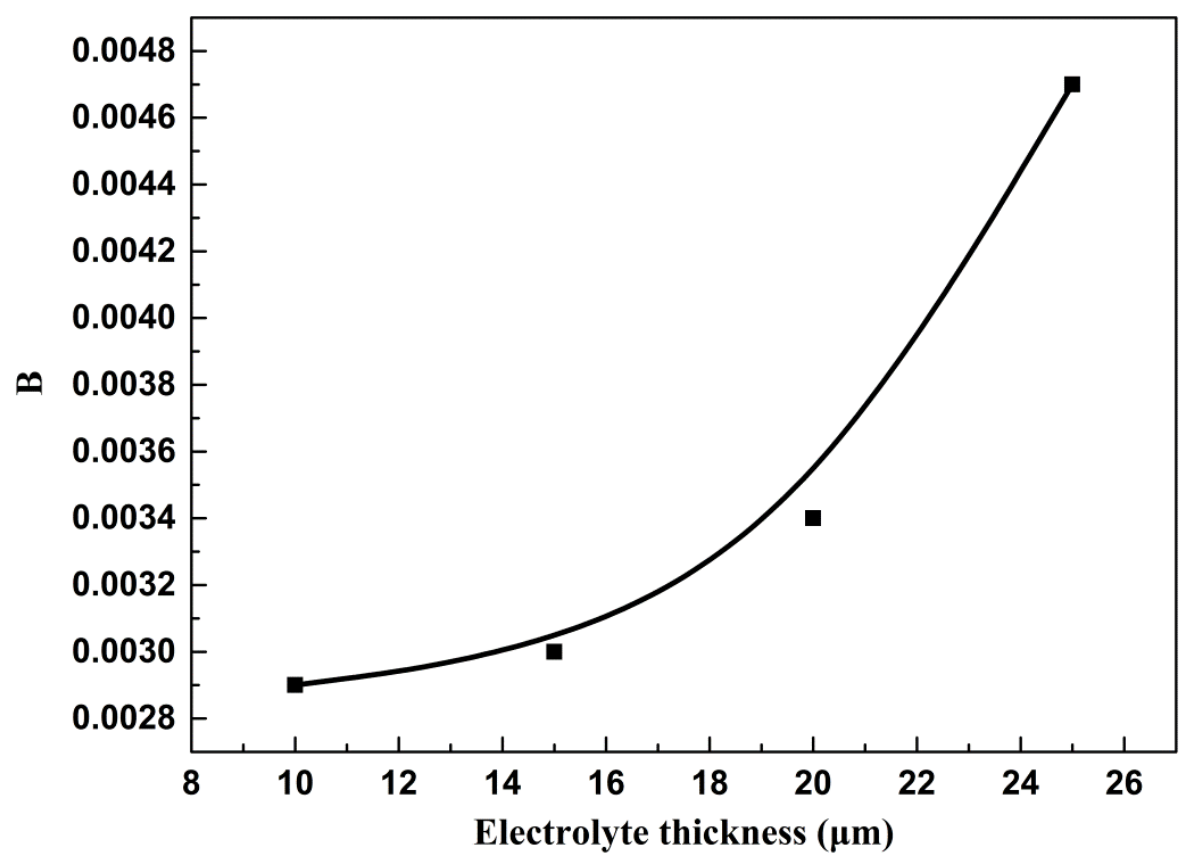

Fig. 7(b) 